\title{
O Programa de Pós-Graduação em Educação da UFPR: vinte anos de lutas e conquistas *
}

\section{The Education Graduate Program of UFPR: twenty years of struggles and achievements}

\author{
Tânia M. Baibich-Faria**
}

O Setor de Educação da Universidade Federal do Paraná está em festa. Comemoramos neste ano os 30 anos de existência de nosso Programa de Pós-Graduação em Educação. A atuação dos profissionais que construíram este programa está inscrita para sempre na história da educação do Estado do Paraná e do Brasil. Esta é uma platéia "mapa de referência", isto é, "mapas" de idéias, de lutas, de produção acadêmica, política, cultural, além de "mapa" de administradores das mais distintas e significativas instituições de educação.

Neste lugar de honrada responsabilidade acadêmica e social, no momento em que alcançamos os 30 anos deste programa público de PósGraduação em Educação, avaliado nacionalmente por seus pares como de elevada qualidade, entendemos que, a um só tempo, nossa tarefa pela manutenção e pelo aprimoramento da qualidade alcançada deve iniciar e pautar-se pelo reconhecimento, pela gratidão e pela luta permanente e coletiva por um crescimento com compromisso social. Na contemporaneidade, momento em que a história, os personagens e as ações se apequenam fren-

* Discurso proferido na posse da coordenação do Programa de Pós-Graduação em Educação da Universidade Federal do Paraná - UFPR, em 16 de dezembro de 2006.

** Coordenadora do Programa de Pós-Graduação em Educação - PPGE/UFPR, gestão 2006-2008. Vice-coodenadora - Profa. Dra. Maria Tereza Carneiro Soares. 
te à lógica perversa da competição, do individualismo e do consumo rápido, optamos pela contramão da história, parafraseando Walter Benjamin.

Talvez bastasse, para que compreendêssemos a inteireza do significado destes 30 anos, que, ao invés de um discurso, cada um de nós olhasse para a platéia que hoje orna este salão de conferências e reconhecêssemos nos rostos presentes o significado do que aqui hoje comemoramos. Até mesmo o mais desavisado transeunte poderia reconhecer que esta platéia congrega inúmeros significativos nomes da Educação Paranaense e Brasileira. Temos hoje aqui, nesta cerimônia, um grande número de intelectuais paranaenses, cuja luta pela educação pública, gratuita e de qualidade socialmente referenciada, iniciaram a construção daquilo que nos identifica, com a feição que hoje nos é própria, nós no Programa de Pós-Graduação em Educação, no Setor de Educação, na UFPR e no Estado do Paraná, com nossa face e nossa alma.

Entretanto, não há como abdicar do privilégio de contar mais uma vez esta história, prestando uma reverência profundamente afetiva, mas também institucional, a todos que para o engrandecimento deste Programa, ao longo destas três décadas, empenharam o melhor de seus esforços. A história de cada uma das pessoas que está aqui é uma história de enfrentamentos: dos conflitos e das contradições inerentes a qualquer atividade humana em sociedade; das agruras do sempre quase naturalizado parco investimento governamental na educação pública brasileira; das malhas da burocracia; das políticas que redundaram em inúmeras aposentadorias e que tornaram quase impossível para os que ficaram manter o programa vivo; enfrentamento dos ataques de todas as ordens ao ensino superior público e gratuito; dos "labirintos e seus minotauros" que precedem à criação de um curso de Doutorado e, por fim, da manutenção e da qualidade destes cursos. Como diria Guimarães Rosa, no seu Sertão, enfrentamento do "vai-vem da vida burra", e nestes enfrentamentos permitindo com que chegássemos até aqui.

Aos colegas, muitos destes nossos queridos e respeitados ex-professores, muitos nossos mestres permanentes, dedicamos esta solenidade de posse. Somente estamos aqui porque eles aqui estiveram nos antecedendo, nos formando, forjando e legando-nos esta herança que, parodiando Goethe, temos buscado conquistar para que um dia possa ser nossa.

Nossa luta neste período que se inicia, luta que vimos travando em outras instâncias tão importantes quanto esta da vida universitária, como no ensino, na extensão, nas atividades administrativas e de representação, no sindicato, será uma luta sem trégua na defesa da Escola Pública de qualidade, voltada para a formação e para a produção de conhecimento 
novo, cuja finalidade seja a justiça social, a garantia dos direitos de cidadania, o exercício da democracia, o respeito à natureza e à condição humana, o acesso de todos ao conhecimento e à riqueza socialmente produzida, além da luta pela pedagogia do antipreconceito.

Dando continuidade ao importante trabalho de manutenção e aprimoramento do PPGE, desenvolvido pelas gestões que nos antecederam, buscaremos resguardar e aprimorar a qualidade do programa. Para tanto, nos comprometemos a coordenar duas grandes batalhas em distintos campos de luta. Seguiremos cumprindo a política atual de avaliação das agências financiadoras da pós-graduação, atuação esta que nos permitirá lutar com equilíbrio de forças com que lutam os melhores programas do país, por reconhecimento e recursos - de acordo com as regras atualmente definidas por nossos pares. Concomitantemente, atuaremos junto ao Fórum de Coordenadores de Pós-Graduação da UFPR e ao Fórum de Coordenadores de Pós-Graduação em Educação do país, bem como às coordenações dos órgãos de fomento Capes, $C N P q$ e demais agências, para que possamos trocar idéias sobre as concepções de avaliação e de financiamento da Educação Superior no Brasil, inclusive da Pós-Graduação. Os processos de avaliação deverão respeitar a diversidade, a qualidade, o impacto social, o mérito acadêmico, sem nos pautarmos por uma lógica da produtividade estéril e sem propósitos intelectuais e sociais. No âmbito interno ao Programa de Pós-Graduação em Educação - PPGE, visaremos ainda criar, coletivamente, uma política de avaliação, no intuito de diagnosticar a situação atual, além de discutirmos metas de aprimoramento.

É também nosso propósito a ampliação dos espaços democráticos de socialização do conhecimento produzido na universidade. Neste sentido, visamos criar eventos de divulgação, voltados ao público em geral, sobre as pesquisas em andamento, no sentido de incrementar as relações com as demandas dos diferentes sistemas de ensino público, conforme as diversas linhas de pesquisa do programa vêm fazendo. Também é nossa intenção já manifesta o estímulo à criação de fórum de debates político-acadêmicos que congreguem discentes e docentes e que sejam abertos a outros programas.

Esse compromisso que assumimos nessa coordenação é o compromisso de um programa e um compromisso coletivo. Trata-se de um compromisso que possui o olhar voltado para o futuro, que espera ser transformador, tem os pés no presente, que sabe ser espaço de ancoragem e de vinculação com a concretude da vida e que tem os laços da história como garantia de uma sólida construção. A história da Pós-Graduação em 
Educação da Universidade Federal do Paraná começou há 30 anos atrás, carreada pela visão sempre contemporânea da então Diretora de Setor de Educação da UFPR, Zélia Milleo Pavão, nossa muito admirada e querida professora, e do Lauro Esmanhoto, "pai" do primeiro projeto e primeiro coordenador do Curso de Pós-Graduação.

Também naquele momento e antes e depois, uma pioneira incansável, com sua figura quase "quixotesca", marcou para sempre a história deste programa e desta universidade: nossa querida Professora Eni Caldeira, hoje nome de escola, o que por si mesmo declara seu valor para a Educação do Estado do Paraná. A ela, em memória, nosso muito obrigado.

Outro professor pioneiro incansável, contemporâneo destas imponentes figuras, responsável pela organização e até mesmo pelo financiamento da primeira publicação da produção acadêmica discente deste programa, foi o Professor Ângelo Visentin. A ele nossos respeitos e nosso muito obrigado.

Em seguida, nossa homenagem é para o Professor Eugenio Barthelms, coordenador do programa por duas gestões sucessivas, na primeira tendo como vice o Professor Alvino Moser, e na segunda o Professor José Alberto Pedra. Ao Professor Barthelms, que sempre primou por manter a alegria no mesmo compasso do trabalho sério, nosso muito obrigado.

Professora Heloísa Lück, cuja exigência consigo e conosco, seus alunos, constituiu uma marca de sua busca pelo melhor, foi a coordenadora seguinte do programa. A ela nosso reconhecimento e nosso muito obrigado.

Professora Onilza Borges Martins, tendo como vice a Professora Maria do Rosário Knechtel, mulheres à frente dos tempos, que imprimiram a este programa uma abertura sem par e que conseguiram a primeira bolsa institucional para um aluno de mestrado. A estas mulheres, nosso muito obrigado.

Professora Rejane de Medeiros Cervi, tendo como vice numa primeira gestão o Professor Mozer e numa segunda o Professor José Alberto Pedra, outra mulher guerreira na defesa, sem tréguas, da pós-graduação do Setor de Educação, e também parceira do professor Visentin na organização e financiamento de nossa primeira publicação discente, nosso reconhecimento.

Professor José Alberto Pedra, ex-Diretor do Setor de Educação, que tendo como vice a Professora Maria Cecília Marius de Oliveira, coordenou e contribuiu sobremaneira com o programa e que, em momento de extrema fragilidade do mesmo programa, o sustentou, como professor orientador, juntamente com as pesquisadoras Professoras Maria Lúcia Moro e Acácia 
Kuenzer, sustentaram nos ombros a sobrevivência deste Programa de PósGraduação em Educação. A ele, e também às professoras, nosso muito obrigado. Além desse episódio, as Professoras Maria Lúcia e Acácia, para nosso privilégio, ambas professoras aposentadas, permanecem em franca atividade neste programa.

Professora Maria Tereza Carneiro Soares, que tendo como vice a Professora Maria Lúcia Faria Moro, ambas pesquisadoras reconhecidas nacionalmente na área da Educação Matemática, deixaram também uma importante marca na administração deste programa e generosamente, para meu privilégio, compõe comigo a gestão que ora se inicia.

Professora Maria Auxiliadora (Dolinha) Schmitd que, tendo como vice a Professora Marta Pinheiro, abriu literalmente as portas da coordenação do programa. À elas nosso muito obrigado.

Professores Carlos Eduardo Vieira e Marcus Levy Albino Bemcosta, pela seriedade e competência com que exerceram a coordenação deste programa, nosso muito obrigado.

Professoras Lígia Klein e Regina Michelotto, ambas e envolvidas com a qualidade do ensino público, na coordenação e vice-coordenação, respectivamente, muito obrigado.

Professor Marcus Taborda Oliveira e Professora Cláudia Barcelos, que hoje concluem seu mandato à frente deste Programa e que reiteradas vezes nos mostraram que democracia, respeito, compromisso, rigor acadêmico, são qualidades exercidas no dia-a-dia do fazer universitário. A eles, que carinhosa e cuidadosamente nos entregam o programa, nosso muito obrigado.

Hoje somos um Programa de Mestrado e Doutorado, avaliado pelos pares como programa de alta qualidade. Nossa revista, de excelência, com nota A no programa QUALIS/Capes, acaba de ser incorporada no SCIELO, base virtual de dados que disponibiliza os artigos de forma imediata via eletrônica.

Da mesma forma como a Profa. Zélia Pavão foi a Diretora de Setor que com sua luta e deu à luz o Mestrado, a Profa. Acácia Kuenzer, referência nacional da Educação, ex-Pró-Reitora por duas gestões, ex-representante na Capes, representante no $\mathrm{CNPq}$, nossa primeira professora aposentada voluntária no Programa, foi a Diretora do Setor de Educação que criou o Curso de Doutorado. Sob o comando decidido de sua firme batuta, contando com o currículo dos/as professores/as, Maria Auxiliadora Schmitd, Maria Lúcia Moro, Maria Tereza Carneiro Soares, Noela Invernizi, Leilah Santiago Bufrem, Lígia Klein, José Henrique de Faria, Carlos Vieira, Marcus 
Levy e Serlei Ranzi, também nossa ex-diretora de Setor, e o seu próprio, alcançou a criação deste que hoje é o único Doutorado Público em Educação do Estado do Paraná. A ela e aos colegas citados nosso profundo reconhecimento.

Todavia, como este programa é feito de "madeira de lei", e não só de grandes professores mas também de grandes alunos, esta história pode ser contada para prestar uma homenagem aos primeiros alunos do PPGE. Inicio assim, mencionando três nomes que, além de terem atuado como educadores, deixaram sua marca no Conselho Estadual de Educação; são eles o Professor Arquimedes Maranhão, também nosso ex-Diretor de Setor e Diretor do CETEPAR; a Professora Lílian Wachowicz, também Diretora da Fundepar e a Professora Maria Dativa de Salles, cuja atuação na formação permanente dos movimentos sociais e sindicais ligados à educação a tornou uma referência do ensino público paranaense.

Nessa cerimônia de posse, tendo o privilégio de contar com aqueles e aquelas que com suas presenças fazem no cotidiano sermos quem somos, nossos alunos, professores, servidores técnico-administrativos, e aqui cito nominalmente as Senhoras Darci, Francisca e Irene, técnicas-administrativas e sobretudo esteios de todo nosso trabalho; nossos demais colegas do Setor de Educação e desta universidade, com a presença dos colegas e amigos que ao longo dessas três décadas fizeram com que fôssemos o que hoje somos, e mais, podendo festejar o fato de construirmos coletiva, árdua e prazerosamente durante 30 anos, um conhecimento voltado para a paz, para a justiça social, para o bem comum, creio que estamos todos de parabéns.

Para finalizar, desejamos, Maria Tereza e eu, que todos tenhamos muita sensibilidade para não deixar de ouvir a sociedade, os pares, os alunos, nesta gestão que ora se inicia, e também muita humildade para imitarmos os colegas hoje homenageados, além de muita criatividade para inventarmos um pouquinho o sentido de também escrevermos com capricho, coerência, responsabilidade e crítica, mais um fragmento dessa história.

Há 50 anos, nas Grandes Veredas do Sertão, Guimarães Rosa dizia que:

Só quando se tem rio fundo, ou cava de buraco, é que a gente por riba põe ponte... 
Assim, vida quer da gente coragem. A nossa realidade é funda. Que façamos juntos muitas pontes.

Texto recebido em 02 fev. 2007

Texto aprovado em 12 fev. 2007 